\title{
Can the Triumphant March of TB be Stopped? A Critical Appraisal of the Currently Applied Policy of Eradication
}

\section{Roland Maes*}

Anda Biologicals, Strasbourg, France

“Corresponding author: Roland Maes, Anda Biologicals, Strasbourg, France, Tel: + 0033388501948; E-mail: anda.mars@wanadoo.fr

Received date: May 21, 2016, Accepted date: June 25, 2016, Published date: June 30, 2016

Copyright: ( 2016 Maes R. This is an open-access article distributed under the terms of the Creative Commons Attribution License, which permits unrestricted use, distribution, and reproduction in any medium, provided the original author and source are credited.

\begin{abstract}
The fight against TB is organized by International (WHO, International Union of Tuberculosis and Lung Diseases (UTLD) and National organizations (Ministries of Health). Their strategy is based on a "herd medicine" approach. The vaccine and the massive administration of four drugs (isoniazid, rifampicin, ethambutol and pyrazinamide-with streptomycin eventually added for the resistant cases) worldwide during decennia were expected to solve the TB problem. They did not because the means applied to fight the disease were not appropriate. The BCG vaccine is the only vaccine in use, yet it sometimes promotes TB multiplication instead of eradication; only four drugs were imposed by Standard Operating Procedures during decennia, of which some are immunodepressive and may, under some conditions, add to the immunodepressive activity of the pathogen and favour relapse; the diagnosis limited to the detection of the pathogen ignores the immune condition of the patients under treatment.

The prognosis, diagnosis and treatment of tuberculosis can be improved. The BCG vaccine is iatrogenic and needs replacement; diagnostic tests based on the detection of the pathogen have their use but need to be completed with the detection of asymptomatic cases and the monitoring of the immune status of the treated patients with a sero-diagnostic test that detects unapparent infections and immune-depressed cases; the drugs used to fight TB must be re-evaluated and complemented by the application of immune-stimulating products to those refractory patients who show a need therefore. The continuing use of an iatrogenic vaccine and of immunodepressive drugs defeats the purpose.
\end{abstract}

Keywords: TB-Diagnosis; TB-prognosis; Standard operating procedures; Chemotherapy; immunotherapy; M. Vaccae, BCG; Serodiagnosis; DOT

\section{Introduction}

Tuberculosis is known since time immemorial but became a scourge when the industrial revolution concentrated a pauperized population in insalubrious neighbourhoods and insalubrious industrial complexes. The Ministries of Health of industrializing nations set up a "work medicine" department designed to meet the mounting challenge and the fight against TB was vigorously initiated by the WHO after World War II with the vaccine BCG and four drugs applied to diagnosed TB patients. "Find the bug and stamp it out "was thought to be sufficient to stop the spread of the disease. It did not. Textbooks, publications, communications and posters were produced in huge numbers yet proved powerless in stemming the tide. Among them, I choose a few representatives for analysis and will show that the problem of TB, i.e. the vaccine, the drugs, the diagnosis and the prognosis, was adequately posed but that the results were misinterpreted or else ignored, up till today.

Lignières contested in 1927 the claim of effectiveness and innocuity of the BCG vaccine developed by Calmette and Guérin (Bacille Calmette Guérin) at the Pasteur Institute [1] and the vaccine was consequently put on hold. After World War II, the UNICEF, pushed by Frenchman Debré, chairman of its Subcommittee on Medical Projects and brother of the French prime minister, donated 3 million dollars-a huge amount-to WHO to test the vaccine and impose the BCG vaccination. In 1978, Henry Quiquendon divulged that the WHO had observed an excess of TB cases among vaccines in Finland and Denmark [2]. This evidence of mal-function was obliterated and the WHO secured for the BCG its monopoly worldwide up to the present time. The vaccination of the population of the French Empire and of Libya with the BCG vaccine against tuberculosis started in 1950. Local Public Health officers reported excess TB cases among the vaccines [3]. Forty years later, Pr. Grosset mentioned 10,000 new TB cases in France and concluded that the fight against TB was a total failure [4].

The WHO and UNICEF provided support for a BCG Vaccine Production Center in Guindy, Madras/Chennay, in 1948. Vaccination was extended to schools in almost all states of India in 1949. In 1950, Benjamin reported that tuberculosis infection was so widespread that no part of the country was free from it. A crushing observation was the vaccination of 260,000 Indians in 1970 in Chennay (the Chingleput trial), which resulted after a year in a $100 \%$ excess of symptomatic TB cases among the vaccines [5].

To salvage the BCG, a committee appointed jointly by the ICMR and the WHO acknowledged that the BCG is powerless against lung TB-without admitting that it triggered diagnosed infections in excessbut that it could provide substantial protection against childhood forms of TB such as tubercular meningitis and miliary TB; it was recommended to give the vaccine before the end of the first year after birth. That the BCG may induce tuberculous meningitis instead of preventing it was reported as early as 1928 [1] and was restated in 1988 [6]. However, this evidence was negated in 1991 [7] and the distribution of the BCG continued unabated worldwide. 
In 2001, Eisner and Ehrlich published: "Some congratulations are in order. To the tuberculosis bacillus, for its unexpected renewed success..." [8]. The very same year, a review article named the culprits: "grounded fear of the next great plague, whatever it may be, fueled by global travel, population density, poverty, and stupidity"... This incisive analysis of the TB situation indicted TB-actors with a very harsh word [9].

In 2007, CD Wells warned the mycobacterial community that the combined impact of HIV and Multi Drug Resistant-TB (MDR-TB) will render the problem these pose, intractable [10]. The Indian Ministry of Health confronted the problem in 2012 with an ambitious Revised National Tuberculosis Control Programme (RNTCP) [11], which consisted in a better identification of the patients and their intensified care $[12,13]$. Under the guidance of WHO [14], the RNTCP banned all sero-diagnostic tests in use in the country and promoted the use by the public sector, along with traditional sputum tests, the newly developed Xpert/RIF diagnostic test based on a molecular methodology, able to recognise rifampicin-resistant strains in sputum, as the initial diagnostic test in individuals suspected of multi-drug-resistant (MDR)-TB or HIV-associated TB. The consistent care of patients with first-line and second-line drugs delivered by the public sector completed the policy.

On February 11, 2013, the British Medical Journal announced: Tuberculosis looks set to defy concerted efforts to treat it successfully with powerful drugs, turning the clock back to the 1930's. On February 20, 2013, The Wall Street Journal added: "India's new strategy actually makes disease more drug resistant, doctors say". On January 9, 2014, a post on the LinkedIn group "Healthcare India" complained: "there is a huge possibility of medication or diagnostics being advised disproportionate to the need, and people at large feel that is what is happening".

The UK All Party Parliamentary Group on Global Tuberculosis evaluated on 24 March 2015 the number of deaths due to DrugResistant TB at 75 million people by 2050, at the cost of 16,200 billion Swiss francs. Thirty nine days later, on May 2, Mr. O'Neill, head of a government-backed commission looking into antimicrobial resistance, asserted on BBC News that new anti-microbial drugs were the answer to the spread of multi-resistant TB strains. According to him, 10 new key drugs over the next decade are needed. They would cost about \$25bn at the expense of taxpayers. The WHO backed this position: the Stop TB partnership advocates Ciprofloxacin, Bedaquiline [15] and Delamanid in addition to the regular regimen to meet the surge of MDR-TB in the immediate term, adding to the list any drug that might appear effective.

On July 2015, the Indian NGO Praja.org reported an increase of total cases of TB in Bombay from 30,675 in 2011-2012 to 42,837 cases in 2014-2015. There is clearly something wrong with the currently applied policy. On $1^{\text {st }}$ September 2015, some Asian countries bordering the Pacific expressed their will to counter vigorously the MDR-TB that looms. The UK All Party Parliamentary Group on Global Tuberculosis stepped in on 22 November 2015. The University of Harvard expressed its concern and interest on October 26, 2015 [16].

\section{What are the Problems?}

The "Stop TB partnership" denied during decennia that there was a problem and asserted that the mortality rate due to TB dropped by 45\% between 1990 and 2013 due to improved diagnosis and treatment. It stated on 15 April 2015 its satisfaction with the policy pursued, notwithstanding the inexorable surge of MDR-TB. There is no doubt that the WHO registered some positive results, but could it have done better and is the menace of MDR-TB discarded?

I proceeded to an evaluation of some publications and posters produced during these last decennia and will show that the conclusions drawn from the evidences they expose are false or else were ignored. For events that occurred before the end of WWII, I relied on the book entitled the failure of the BCG. Testimonies of yesterday and of today. Chronicle of an announced failure" [3], in French: "La faillite du BCG. Témoignages $d^{\prime}$ hier et $d^{\prime}$ aujourd'hui. Chronique d'une faillite annoncée.

The magnitude of the problem currently posed by Tuberculosis demands first an evaluation of the competence of the organisms in charge of the fight. This appraisal will thereafter address the value of the BCG vaccine and show that it is sometimes iatrogenic. The third subject will address the efficiency of the drugs and show that their effectiveness may lead to an immune suppression that may impair lasting recovery, and the last subject is the diagnosis and prognosis policy, which overlooks means allowing taking preventive and ancillary curative measures.

\section{The Mycobacterial Community}

During the golden age of biological research that followed World War II, the biologists knew that their discoveries and developments would be exploited by clinicians, and many diseases and ailments were reduced thanks to this cooperation and mutual trust. This symbiosis between laboratory scientists and clinicians was not the case in the field of Tuberculosis, where the problem is currently handled essentially by the WHO and the International Union against TB as well as the National Ministries of Health. Although one of their essential missions is to seek collaboration with external research units, they only comply if these contributions do not challenge their beliefs or the paradigm under which they currently operate. Under their guidance, the $\mathrm{TB}$ problem was thought solved about 50 years ago by the immunization with the BCG vaccine available since 1950, by the use of four specific drugs for cure (isoniazid available since 1952, rifampicin, ethambutol and pyrazinamide, plus streptomycin available since 1944) and a diagnostic method based on detection of mycobacterial antigens in sputum or other organ. The problem posed by TB is handled today with the concepts that were in force during the $19^{\text {th }}$ and $20^{\text {th }}$ century. The technical skills involved in new sophisticated methods of detection help hiding the poverty of the results obtained.

\section{The Paradigmatic Deviations}

\section{The value of the BCG vaccine}

With billions of doses of Bacille Calmette-Guérin (BCG) vaccine distributed over the past fifty years, with $85 \%$ of the world population vaccinated but with a third of the world population infected, the epidemiological proof of the failure of the BCG vaccine is given.

The first warning that the BCG was not fully attenuated was given in 1927 [1]. A second warning that the mass vaccination with BCG generated TB cases in excess was given in 1978 [17]. The regression of the tuberculous endemy grinded to a halt in France in 1987, followed with a 7\% increase of TB cases in 1992 versus 1991. Pr Grosset mentioned 10,000 new cases in 1994 in France and concluded that the fight against TB was a total failure [4]. Janet Cornwall replied tartly in 
Page 3 of 7

1997 [18] that the reason for the failure was the corruption, greed and ineptness of the TB-actors anxious to earn profits incommensurate with the health benefits they were supposed to provide.

The Netherlands, Germany, the USA, the UK and other countries refused the BCG, a measure that in no way favoured in these countries the endemy above that observed in covered countries.

Early evidence of inefficacy of BCG: Calmette attenuated a strain of $M$. bovis during 13 years by repeat subculture in vitro. The live bacillus so obtained limited, in guinea pigs, the dissemination of inhaled TB bacilli towards the liver as well as their secondary dissemination towards the lung. The vaccine lent no protection at all to monkeys at risk [3].

Proof of protection based on tuberculin allergy: In the year 1926, the positive results obtained with guinea pigs prompted Calmette to vaccinate children, who were kept in a protected environment. He observed in 1928 that the BCG reduced by $3 / 4$ the tuberculosis mortality and by half the general mortality. The English statistician Greenwood retorted that the results were flawed because the vaccinated children were under tight medical supervision by nurses who fed them well and cared for them whereas the unvaccinated children used as controls were living in the slums of France. The general infantile mortality in the protected environment where vaccinated children were kept was $17 \%$ in 1922 and had dropped to $5.1 \%$ in 1926 , at the moment they were vaccinated, indicating that the reduction in mortality in the protected environment started well before the vaccination took place.

The proof of efficacy of the vaccine was, according to Calmette, the skin-allergy (i.e. the tuberculin test) it elicited. Calmette observed that $28 \%$ of the vaccines reacted positively on an intradermal tuberculin injection. These $28 \%$ reactors were half the frequency of reactors observed by Calmette at the same time among non- vaccinated children kept in an open environment, which amounted to $60 \%$.

Calmette attributed this twofold increase in reactivity to an unapparent tuberculosis infection but did not consider the possibility that the $28 \%$ positive skin tests observed among the vaccinated children were also due to cryptic TB infections. He linked the positive skin test observed in vaccines to a protective activity of the BCG vaccine. This allergy, observed in only $28 \%$ of the vaccines, was erroneously taken as proof that the vaccine had been efficacious and protective. A second vaccination was recommended if the first one had not elicited a positive tuberculin reaction.

Comstock observed in 1994 [19], i.e. at the same time Grosset noted the failure of the vaccination in France, that the vaccines he followed in the Chingleput trial responded either not at all to a skin test or else with an induration similar to the one obtained with TB patients. He also observed that the positive response was obtained mainly among vaccines who had been former TB patients. These clues indicate that the BCG does not induce a tuberculin reaction but causes the reactivation of $\mathrm{TB}$ infections.

The skin allergy induced by a BCG inoculation was found in 1999 in Saudi Arabia to be of the order of $7.8 \%$, five years after vaccination. An Italian study performed at the same time [20] attributed a skin induration superior to $11 \mathrm{~mm}$ in vaccinated subjects not to BCG but to a tuberculosis infection. In other words, the BCG does not or only rarely induce a DTH reaction. These observations made 21 year and 16 years ago were published as obscure posters and drew no attention.

\section{Controlled vaccination campaigns}

The first Congress of BCG was held on the 18th of June 1948 at the Pasteur Institute. Notwithstanding the absence of an allergy to tuberculin in $72 \%$ of the children vaccinated by Calmette in 1926, it confirmed unanimously (with one abstention) that BCG provokes within a short time a neat and lasting allergy detected by tuberculin. The French State approved the BCG vaccine in 1950, made it compulsory and initiated the vaccination campaign in its colonies Djibouti and Madagascar. The WHO distributed the vaccine in Libya. The efficacy of the vaccine was not monitored but local Public Health officers reported excess TB cases among the vaccines [3].

Indian villagers vaccinated in 1950 showed an excess of $90 \%$ ТВ cases among the vaccines [17]. The promotion of leprosy by BCG was published in 1960 and again in the nineties [21-23]. A 9 fold excess of leprosy cases which affected only vaccines less than 5 years old was observed in New Guinea, a TB-free zone, during the first five years following BCG vaccination [24]. The vaccination of 260,000 Indians in 1970 in Chennay (the Chingleput trial followed by Comstock) resulted after a year in a $100 \%$ excess of symptomatic TB among the vaccines. Four years after vaccination, the excess in symptomatic cases was $150 \%$ [5]. These excesses were resorbed in the following years.

The infectiousness of the BCG was reported again in 1988 [6]. It was negated in 1991 [7], the occasional iatrogenicity of the vaccine being attributed to interference from other pathogenic entities in 1995 [25]. To justify its continued use, two specific claims were made: claim of protection given by the vaccine to children and claim that the vaccine is useful in severe forms of the disease, essentially tuberculosis meningitis.

In Hong Kong, a vaccination campaign started in 1954. It claimed a reduction of infant TB mortality rate from $100 \%$ to $0 \%$ within 16 years. This decrease commands admiration and adhesion but was in all likelihood not due to the vaccine but to the progresses in public hygiene and alimentation that were registered at that time in Hong Kong. Hidden was the fact that TB case rates in Hong Kong had decreased by $25 \%$ and infant TB mortality rate had decreased by $40 \%$ within the two years that preceded the vaccination campaign [26].

BCG is claimed to protect preferentially against severe forms of the disease [7] yet BCG sometimes induces meningitis [6] and the mortality due to tuberculosis meningitis extends to vaccinated patients: in a study performed in Tehran on 100 children suffering from meningitis [27], $10 \%$ responded to a tuberculin test, $22 \%$ were meninges-smear positive and $39 \%$ were meninges-culture positive. Of the 30 children with a history of vaccination, $9 / 30$ died (30\%) versus $20 / 70(28.6 \%)$ among the non-vaccinated children. These percentages of mortality are similar. The vaccine did not conclusively protect against death but the authors mention however that the complications were much more pronounced among the non-vaccinated survivors, indicating that the vaccine helped in these cases. The vaccine does sometimes perform well and in other cases not.

The PNAS USA published in 1997 that the epidemic of TB occurring after the vaccination of an Amazonian tribe with BCG in 1994 was due to its immunological naivety [28]. However, the first case of TB among the Yanomami was observed in 1965, with more cases appearing in the 1970's. The population was vaccinated in 1994 because tuberculosis cases were uncovered among its members. The population was exposed to TB before the vaccination took place and the TB patients present in its midst did not cause an epidemic. The result of the vaccination was that $82 \%$ of the vaccinated population 
contracted TB. Immunological naivety had nothing to do with this epidemic. The epidemiological proof that the origin of the epidemic was the vaccine is indisputable.

\section{The tuberculin proof of the iatrogenic activity of BCG}

The capacity of the BCG to favour infections by M. tuberculosis or reactivations of dormant infections was formally demonstrated in a Swedish study analysing the sensitivity to tuberculin of vaccinated and non-vaccinated children [29]. Three percent of the non-vaccinated controls were tuberculin-reactive, versus $49 \%$ of the vaccinated children. The children in Sweden spend the long dark winter months at home, caring for pet animals (birds and fishes). The Swedish investigators controlled the skin reactivity of their subjects not only with tuberculin but also with avianin and scrofulascein, which would indicate infections with $M$. avium and $M$. scrofulasceum, mycobacteria that infect birds and fishes. They found that $58 \%$ of the vaccinated children reacted to scrofulacein and $67 \%$ to avianin, while the frequencies found with these two sensitins in non-vaccinated children were only $25 \%$ for scrofulacein and $32 \%$ for avianin. The investigators concluded that BCG favored infections by atypical mycobacteria but they remained prisoners of the paradigm under which they worked and refused to extend this obvious conclusion to tuberculosis.

The failure of the BCG to provide protection was shown by the monitoring of IgM and IgG antibodies' production against various mycobacterial antigens by vaccinated babies; it showed the absence of production of antibodies of the IgG class against a dominant thermostable BCG antigen (antigen 60) [30], indicating that the vaccination did not induce the synthesis of protecting antibodies.

\section{The specificity of BCG antibodies}

Middlebrook reported in 1974 [31] no benefit of a transfer of immune serum to rabbits experimentally infected with TB. The consequence of this observation was that attention focused on cellular immune responses only, in human infections. Human tuberculosis was assumed not to induce the formation of circulating antibodies, which, if ever formed, were claimed anyhow inoperative in the recovery of patients [32].

The tuberculosis disease is scientifically and medically complex [33-36]. The immune response against $M$. tuberculosis proceeds in four overlapping stages. The first response is innate and is addressed against the whole bacterium by the production of Nitric Oxide by macrophages. The second response is specifically directed against low molecular weight non-peptide antigens that constitute $95 \%$ of the mycobacterial surface. Antibodies against small molecular weight nonpeptide antigens are detected during primary infections. A serological test based on these antigens may be useful for the diagnostic of TB in children [37].

If the host is unable to eradicate the pathogen, he mounts an immune response against large molecular weight lipoarabinomannan (LAM) and mycolic acid, which are embedded in the mycobacterial cell wall. At that level of infection, the bacterium suppresses immune responses against protein antigens [38]. These patients need external help, under the form of a therapy. If left unaided, the patient will become chronically infected and eventually die.

The fourth response is specific for peptide antigens that are located within the mycobacterium. This stage may be reached spontaneously by the patient or else is obtained by a successful specific treatment.
Text books on TB either ignore the humoral immune response completely or else rebuff it disparagingly. The WHO banned serological tests [14] on the basis of a meta-analysis conducted in 2011 [39] and on its cost [40]. The analysis proceeded in the ignorance of the various aspects that may present the humoral immune response of TB patients. The American Statistical Association issued a warning on the gross misuse of statistics relying on the $\mathrm{P}$ value for policy decisions [41]: "The society's members had become increasingly concerned that the $\mathrm{P}$ value was being misapplied in ways that cast doubt on statistics generally. In its statement, the ASA advises researchers to avoid drawing scientific conclusions or making policy decisions based on $\mathrm{P}$ values alone".

M. Pai, senior author of the meta-analysis, stated: "Based on the evidence in this updated meta-analysis, and cost-effectiveness analyses, the WHO issued a strong negative recommendation against commercial serological antibody-detection tests for TB diagnosis". The WHO Expert Group Meeting convened by WHO in Geneva on 22 July 2010, and the WHO Stop TB Department both fully endorsed these false conclusions and banned the Anda-TB serology [14].

A study of the specificity of antibodies against BCG and TB relying on a flow-through method [42] demonstrated that antibodies raised by one strain of BCG do not necessarily recognize the surface antigens of pathogenic TB thriving in different towns and countries. Here is a simple explanation for the variable efficacy of the BCG vaccination.

\section{The efficiency of drugs}

SOP and DOTS: It is commonly pretended that the pharmaceutical industry has neglected the development of specific drugs against TB because the market addressed impecunious clients and states. Thirty year ago, several companies invested in $\mathrm{R}$ and $\mathrm{D}$ of new drugs, of which bedaquiline is a representative. They are in the process of being "rediscovered" now that the MDR-TB problem has become intractable. The Standard Operation Procedure (SOP) devised by WHO restricted during decennia the drug regimen to isoniazid, rifampicin, ethambutol and pyrazinamide (plus streptomycin), which excluded de facto further research and development of new drugs because the newly developed drugs would find no outlet.

Streptomycin and rifampicin kill not only TB but also harm the cells involved in the immune defence system. Inclusion of these cytocidal drugs in a treatment has consistently been shown to be beneficial, with treatment failure occurring in $5 \%$ to $10 \%$ of cases but rises sometimes to $44 \%$. This low number (5\% to $10 \%$ ) represents a therapeutic success but also a failure, accentuated by the $44 \%$ failure rate sometimes observed.

The four drugs were administered during decennia at their maximal tolerated concentration. These drugs may very well weaken the immune system of the patient to a point where his immune mechanisms become unable to dispose of the resident live intracellular mycobacteria subsisting after completion of the therapy or its early abandon due to intolerance. In the best of cases, $5 \%$ of the treated patients will relapse. In the worst case, up to $44 \%$ of the patients may relapse and turn resistant to one drug and 30\% resistant to both isoniazid and rifampicin [43].

Nowadays the World Health Organization recommends the use of bedaquiline in the treatment of multidrug resistant tuberculosis [15]. The drug is claimed to inhibit specifically mycobacterial adenosine 5'triphosphate (ATP) synthase, an enzyme essential for generation of 
Page 5 of 7

energy in M. tuberculosis. The drug is known to elicit mycobacterial drug-resistance and associates with a disquieting number of dangerous side-effects. These are waved away in view of the urgency of the problem [44].

Another recommended drug is ciprofloxacin. This broad-spectrum antibiotic is active against both Gram-positive and Gramnegative bacteria. It functions by inhibiting DNA gyrase, a type II topoisomerase and topoisomerase IV, three enzymes necessary to separate bacterial DNA, thereby inhibiting cell division. As a result of its widespread use to treat minor infections readily treatable with older, less broad spectrum antibiotics, many bacteria have developed resistance to this drug in recent years, leaving it significantly less effective than it would have been otherwise.

The WHO has added in 2016 other drugs to its list, as clofazimine and Sirturo $^{\circ}$, which are said to reduce the time of treatment from about two years down to 9 months, and represent a considerable progress these additional drugs are an extension of the current approach that consist summarily in "find the bug and stamp it out!" but WHO does not consider immunotherapeutic approaches addressing the needs of individual patients, which are novel and constructive means to meet the MDR-TB rising peril.

The reduction of the TB problem to detection and compliance [45] applied via a Standard Operating Procedure that allowed no deviation from the recommended drugs, was completed with the concept of Directly Observed Therapy (DOT). The method was successfully applied in New York and other American cities because the number of TB patients was relatively low, because these patients were largely cooperative and because the strong political will to eradicate the disease was backed by almost unlimited funds.

Elsewhere, this policy is unworkable, due to costs, to crippling sideeffects and a difficulty in tracing the patients who want to escape the harsh treatment. The only way to handle these refractory patients seems to be an immunotherapy and/or the boosting of their immune system.

\section{Immunotherapy}

Stanford and colleagues answered the TB challenge in an original way with $M$. vaccae immunotherapy $[46,47]$. However, not all TB patients undergo an abrogation of their immune defenses, inflicted either by the pathogen or else by the drugs used to eliminate the pathogen. The essential contribution of immunotherapeutic agents would be to assist chemicals powerless in the suppression of an established immune-depressive infection. The potential of the immunotherapeutic agent is masked in those patients whose chemotreatment is sufficient to restore their immune defenses and heal the patients [48].

The promoters of the immunotherapeutic approach with $M$. vaccae made no use of a serological test that was able to monitor the humoral immune response of the patients under treatment and select those patients in need of an immunological boost. They recommended applying the immune-treatment with $M$. vaccae at the beginning of the chemo-treatment, on newly diagnosed patients $[49,50]$. The clinical trial in Durban [51] that crucified this approach was conducted on newly diagnosed patients under chemotherapy with 4 drugs. This is a requirement of the Helsinki Declaration but its strict application was inappropriate for the study on immunotherapy.
A single inoculation of $M$. vaccae at the beginning of the shortcourse treatment on patients of whom all the controls not receiving the immune-therapy survived, had an immediate effect so limited that $M$. vaccae immunotherapy was claimed, mistakenly, useless. When the agent is used repeatedly, i.e. injected intramuscularly monthly for 6 months to chronic patients resistant to isoniazid, streptomycin and rifampin, 9 of 24 cases were cured after 18 months follow up, versus 1 of 24 cases in the control group [52]. This communication was divulged as a poster and drew neither notice nor action. This semisuccess indicates that additional means must be applied.

\section{Boosting of the immune response}

The first line of defence against an invading pathogen is the production of the highly reactive nitric oxide by macrophages and other cells $[33,34]$. The antimicrobial properties of Nitric Oxide (NO) are well established since 1995 [53]. NO is active in vivo against mycobacteria [54]. A food supplement promoting the synthesis of Nitric Oxide via uleine [55] is available and cheap compared to drugs. It was shown absolutely innocuous [56] and very efficacious in the treatment of HIV-infected patients [57], with improvement of their health observable after 3 months of daily administration. The Stop TB Working Group on New TB Drugs section of WHO proposed on June 162014 the inclusion of this very cheap and efficacious product in its list of new drugs, and promptly removed it from that list two weeks later.

\section{Prognosis and diagnosis}

The WHO recommends four sputum tests, i.e. sputum smears, Xpert MTB/RIF, line probe assay and liquid cultures, with additional tests in waiting. It promotes an interferon gamma release assay for the detection of latent infections. The interferon gamma release assays (test) consists in drawing one cubic centimetre of whole blood from the subject and incubate the sample during 24 hours at $37^{\circ} \mathrm{C}$ in the presence of at least two peptides specific for M. tuberculosis.

These peptides are meant to stimulate the production of interferon by the T-cells present in the blood. The plasma is thereafter isolated and the presence of interferon assessed either by an enzyme immune essay or by a gold reagent. Interferon is also produced during diagnosed infections but is recommended by WHO to detect latent infections. The interferon test has its uses but is ill-adapted to those countries where cheap prognostic tests are most needed.

Antibodies are produced in latent infections, yet a serological monitoring of exposed groups is not considered because the WHO banned serological tests [14]. The interferon test is a costly substitute to a much cheaper method of assessment of latent infections, by monitoring the humoral immunity. The Anda TB serological test is available since 1989 [58] was shown useful for the detection of latent infections in exposed groups in 1989 [59] and 1990 [60], among some cancer patients in 1995 [61]. Serological measurements also give valuable prognostic and diagnostic clues in BCG vaccinated infants [22].

\section{Conclusion}

Janet Cornwall observed in 1997 that: "For the sake of return on investment and for the justification of huge public subventions and lavish expenditures on research and development, the management of the TB problem has chosen to ignore the reality of the situation and 
the urgency of solutions sensibly adapted to its needs" [18]. Eighteen years later, her observation is still valid.

\section{Competing interests}

Dr. R. Maes has developed the antigen 60 serological tests for TB the flow-through method for detection of TB antigens and the Para Pau aspido food supplement.

\section{References}

1. Lignières J (1927) Contribution à l'étude des qualités pathogènes du vaccin BCG contre la tuberculose. Bull Acad Méd: 127.

2. Quiquandon H (1978) Douze balles pour un veto. Tome II page 185 (edn). Agriculture et vie.

3. Ferru M (1995) La faillite du BCG. Témoignages d' hier et d' aujourd'hui. Chronique d'une faillite annoncée.

4. Grosset J (1994) La tuberculose en France: état des lieux. Impact Médecin Quotidien.

5. Tripathy SP (1994) Fifteen years follow up of the Indian BCG prevention trial. XXVth World Conference of the International Union against TB Singapore 1986. in Clinical Tuberculosis P.O. Davies Eds.

6. Tardieu M, Truffot-Pernot C, Carriere JP, Dupic Y, Landrieu P, et al. (1988) Tuberculous meningitis due to BCG in two previously healthy children. Lancet. 27: 440-441.

7. Grosset J, Schwoebel V (1991) Surveillance active de la méningite tuberculeuse en France en 1990. Bull Epidémiol Hebd 48: 209-210.

8. Eisner T, Ehrlich P (2001) New World Pathogen Strategy Disclosed: Science 292: 2397.

9. Howard (2001) Divergent thinking about Self-Defense. Science 293: 219.

10. Wells CD, Cegielski JP, Nelson LJ, Laserson KF, Holtz TH, et al. (2007) HIV infection and multidrug-resistant tuberculosis: the perfect storm. J Infect Dis 196: S86-107.

11. Sachdeva KS, Kumar A, Dewan P, Satyanarayana S (2012) New Vision for Revised National Tuberculosis Control Programme (RNTCP): Universal access-Reaching the un-reached. Indian J Med Res 135: 690-694.

12. Singh J, Bhan A, Upshur R (2013) Diagnosis of drug-resistant TB and provision of second-line TB treatment in India: some ethical considerations. Ind J Med Ethics 10: 110-114.

13. Babu GR, Sathyanarayana TN, Bhan A, Lakshmi JK, Kishore M, et al. (2014) An appraisal of the tuberculosis programme in India using an ethics framework. Indian J Med Ethics 11: 11-15.

14. World Health Organization (2011) Commercial serodiagnostic tests for Diagnosis of tuberculosis. Policy statement. 1.Tuberculosis - diagnosis. 2.Serologic tests - standards. 3. Guidelines.

15. Expert group meeting report (2013) World Health Organization, Geneva: 1-31.

16. Yuen CM, Amanullah F, Dharmadhikari A, Nardell E, Seddon J, et al. (2015) Turning off the tap: stopping tuberculosis transmission through active case-finding and prompt effective treatment. The Lancet 386 2334-2343.

17. Frimodt-Moller J (1978) Observations on the protective effect of BCG in a South Indian rural population. Bull. Int. Union TB 48: 40-49.

18. Cornwall J (1997) Tuberculosis: a clinical problem of international importance. Lancet 350: 660-661.

19. Comstock G (1994) The international Tuberculosis Campaign: a Pioneering Venture in Mass Vaccination and Research. Clin Inf Dis 19: 528-540.

20. Bugiani M, Arossa W, Cavellero M, Caria E, Carosso A, et al. (1999) Tuberculin reactivity in BCG vaccinated subjects. 30th IUATLD World Conf. on Lung Health. Madrid 118-PD.

21. Wade H (1960) BCG-induced activations. Int J Leprosy 28: 179-181.

22. Muliyil J (1991) Effect of BCG on the risk of leprosy in an endemic area: a case-control study. Int J Leprosy 59: 229-236.
23. Nguyen Van Th, Abel L, Dinh Lap V, Oberti J, Lagrange PH, et al. (1994) Protective effect of BCG against leprosy and its subtypes: a case-control study in Southern Vietnam. Int J Leprosy 62: 532-538.

24. Bagshawe A, Scott GC, Russell DA, Wigley SC, Merianos A, et al. (1989) BCG vaccination in leprosy: final results of the trial in Karimui, Papua New Guinea, 1963-1979. WHO Bulletin OMS 67: 389-399.

25. Fine PEM (1995) Variation in the protection by BCG: implications of and for heterologous immunity. The Lancet 346: 1339-1345.

26. Wong GW, Oppenheimer SJ (1994) Childhood TB in Clinical Tuberculosis P.O. Davies eds (Chapman and Hall medical).

27. Bagghaie N, Masjedi MR, Velayati AA (1999) Accuracy of BCG vaccination in prevention of tuberculous meningitis. 30th IUATLD World conference, Madrid PS 30: 413-PD.

28. Sousa AO, Salem JI, Lee FK, Verçosa MC, Cruaud P, et al. (1997) An epidemic of tuberculosis with a high rate of tuberculin anergy among a population previously unexposed to tuberculosis, the Yanomami Indians of the Brazilian Amazon. Proc Natl Acad Sci U S A. 94: 13227-13232.

29. Larsson LO, Magnusson M, Skoogh BE, Lind A (1992) Sensitivity to sensitins and tuberculin in Swedish children. IV. The influence of BCGvaccination. Eur Respir J 5: 584-586.

30. Rota S, Beyazova U, Karsligil T, Cevheroglu C (1994) Humoral immune response against antigen 60 in BCG-vaccinated infants. Eur J Epidemiol 10: 713-718.

31. Reggiardo Z, Middlebrook G (1974) Failure of passive serum transfer of immunity against aerogenic tuberculosis in rabbits. Proc Soc Exp Biol Med 145: 173-175.

32. Grosset JH, Ji BH (1989) Controlled clinical trial for evaluation of antimicrobial drug activity against M leprae. Int J Lepr 57: 529-531.

33. Maes HH, Causse JE, Maes RF (1996) Mycobacterial infections: are the observed enigmas and paradoxes explained by immunosuppression and immunodeficiency? Med Hypotheses 46: 163-171.

34. Maes HH, Causse JE, Maes RF (1999) Tuberculosis I: a conceptual frame for the immunopathology of the disease. Medical Hypotheses 52: 583-593.

35. Maes RF (1998) A unitarian view of the immunopathology of tuberculosis. Guest Lecture XII National Congress Ind Ass Med Microbiol: 61-70.

36. Maes RF (1998) A conceptual frame for the Immunopathology of Tuberculosis. Second Symposium on Mycobacteria 21-22 April, Ankara: 123-134.

37. Simonney N, Molina J, Molinard M, Oksenhendler E, Lagrange PH, et al. (1996) Comparison of A60 and three glycolipid antigens in an Elisa test for Tuberculosis. Clin Microbiol Inf 2: 214-221.

38. Chan J, Fan XD, Hunter SW, Brennan PJ, Bloom BR, et al. (1991) Lipoarabinomannan, a possible virulence factor involved in persistence of Mycobacterium tuberculosis within macrophages. Infect. Immun 59: 1755-1761.

39. Steingart KR, Flores LL, Dendukuri N, Schiller I, Laal S, et al. (2011) Commercial Serological Tests for the Diagnosis of Active Pulmonary and Extrapulmonary Tuberculosis: An Updated Systematic Review and MetaAnalysis. PLoS Med 8: e1001062.

40. Dowdy DW, Steingart KR, Pai M (2011) Serological Testing Versus Other Strategies for Diagnosis of Active Tuberculosis in India: A CostEffectiveness Analysis. PLoS Med 8: e1001074.

41. ASA (2016) misuse of statistics for policy decisions. Nature 531: 151.

42. Rennou M, Maes MC, Maes HH, Maes RF, Kidwai Z, et al. (2016) Antibodies against BCG and M. tuberculosis H37Ra do not Consistently Recognize Pathogenic M. tuberculosis whole Cells but Recognize their Cytoplasmic Constituents. Implications for the Variability and Protective Efficacy of the Vaccine. Clin Microbiol 5: 2.

43. Nardell EA (1993) Beyond four drugs. Public health policy and the treatment of the individual patient with tuberculosis. Am Rev Respir Dis 148: $2-5$. 
Citation: Maes R (2016) Can the Triumphant March of TB be Stopped? A Critical Appraisal of the Currently Applied Policy of Eradication. Clin

44. Mingote LR, Nabutamba D, Apina F, Barnabas N, Contreras C, et al (2015) The use of Bedaquiline in regimens to treat drug-resistant and drug-susceptible tuberculosis. Lancet 385: 477-479.

45. Enarson D, Grosset J, Mwinga A, Hershfield E, O'Brien R, et al. (1995) The challenge of tuberculosis: statements on global control and prevention. The Lancet 346: 809-819.

46. Grange JM (1997) Immunotherapy: a new strategy for tuberculosis control. Resp Med 91: 1-4.

47. Stanford JL, Stanford CA, Rook GAW, Grange JM (1994) Immunotherapy for Tuberculosis. Investigative and Practical aspects. Clin. Immunother 1: 430-440.

48. Fadda G, Grillo R, Ginesu F, Santoru L, Zanetti S, et al. (1992) Serodiagnosis and follow up of patients with pulmonary tuberculosis by enzyme-linked immunosorbent assay. Eur J Epidemiol 8: 81-87.

49. Johnson JL, Kamya RM, Okwera A, Loughlin AM, Nyole S, et al. (2000) Randomized controlled trial of Mycobacterium vaccae immunotherapy in non-human immunodeficiency virus-infected Ugandan adults with newly diagnosed pulmonary tuberculosis. The Uganda-Case Western Reserve University Research Collaboration. J Infect Dis 181: 1304-1312.

50. Mwinga A, Nunn A, Ngwira B, Chintu C, Warndorff D, et al. (2002) LUSKAR collaboration: Mycobacterium vaccae (SRL 172) immunotherapy as an adjunct to standard antituberculosis treatment in HIV-infected adults with pulmonary tuberculosis: a randomized placebo controlled trial. Lancet 360: 1050-1055.

51. Durban Immunotherapy Trial group (1999) Immunotherapy with Mycobacterium vaccae in patients with newly diagnosed pulmonary tuberculosis: a randomized controlled trial. Lancet $354: 116-119$.

52. Shui-Hua L (1999) Immunotherapy with Mycobacterium vaccae vaccine to multidrug-resistant pulmonary tuberculosis. Abstract book 30th IUATLD World Conference on Lung Health. Madrid S82 Poster 331-PS.
53. De Groote MA, Fang FC (1995) NO inhibitions: antimicrobial properties of nitric oxide. Clin Inf Dis 21: S162-165.

54. Schoendon G, Schneemann M, Walter R, Blau N, Hofer S, et al. (1995) Nitric oxide and infection: another view. Clin Inf Dis 21: S152-157.

55. Souza WM, Brehmer F, Nakao LS, Stinghen AEM, Santos CAM, et al. (2007) Ação da uleína sobre a produção de óxido nítrico em células RAEC e B16F10. Uleine effect on the 18 production of nitric oxide in RAEC and B16F10 cells. Rev. Bras. Farmacogn 17: 191-196.

56. Federlin JD, Maes D, Maes R (2014) Aspidosperma subincanum I. Characterisation, extraction of an uleine-enriched fraction and potential health hazard due to the contaminant ellipticine. Rev Bras Farmacogn 24: 293-297.

57. Maes D, Maes R (2015) Aspidosperma subincanum II. Usefulness of uleine and ribonucleic fragments in the treatment of AIDS patients. Revista Brasileira de Farmacognosia 25: 42-46.

58. Maes R, Homasson JP, Kubin M, Bayer M (1989) Development of an enzyme immunoassay for the serodiagnostic of tuberculosis and mycobacterioses. Med Microbiol Immunol 178: 323-335.

59. Maes R (1989) Incidence of inapparent active mycobacterial infections in France detected by an IgG serological test based on antigen 60 . Med Microbiol Immunol 178: 315-321.

60. Wirrmann C (1990) Public health application of a serological test for tuberculosis: study of the incidence of inapparent infections among employees of an Alsatian supermarket. Eur J Epidemiol 6: 304-308.

61. Kaustova J (1996) Serological IgG, IgM and IgA diagnosis and prognosis of mycobacterial diseases in routine practice. Eur J Med Res 1: 393-403. 